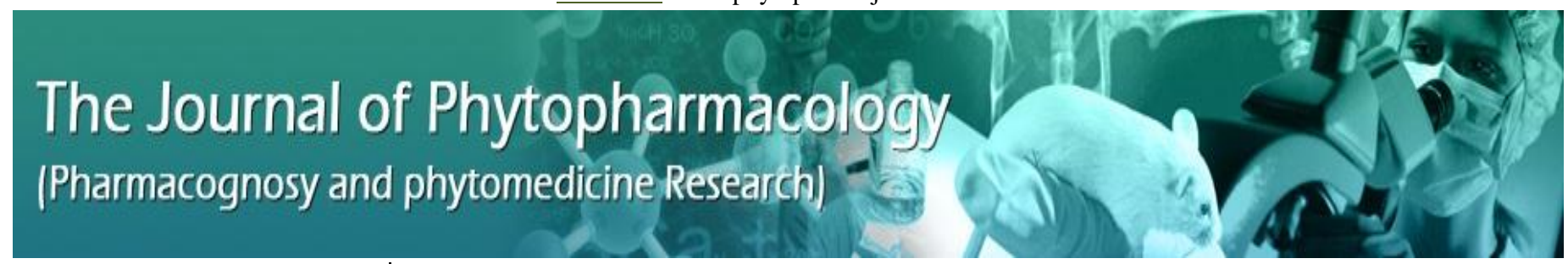

Research Article

ISSN 2230-480X

JPHYTO 2016; 5(1): 35-37

January- February

(c) 2016, All rights reserved

Gereziher Geremedhin Sibhat Department of Pharmacy, Pharmacognosy course and research unit, Mekelle University, Mekelle, P.O.Box: 1871, Ethiopia

Mebrahtom Gebrelibanos Hiben Department of Pharmacy,

Pharmacognosy course and research unit, Mekelle University, Mekelle, P.O.Box: 1871, Ethiopia

Correspondence:

Gereziher Geremedhin Sibhat Pharmacy Department, College of Health Sciences, Mekelle University, Mekelle, P.O.Box: 1871, Ethiopia

Email:

gersh2.mysuru[at]gmail.com

\section{Consequence of concurrent use of chloroquine and hydroalcoholic extract of Balanites aegyptiaca and leaf leatx of Aloe camperi}

Gereziher Geremedhin Sibhat*, Mebrahtom Gebrelibanos Hiben

\section{ABSTRACT}

Prescription and/or over the counter medications when taken together with certain foods or herbal substances, leads to either increase or decrease a drug's therapeutic out comes or adverse effects. It has been reported that a number of plant materials alter some pharmacokinetic parameters of chloroquine when administered concurrently. In some malarious areas of Ethiopia like Tigray region where chloroquine is used as antimalarial drug, medicinal and/or food plants are commonly consumed as herbal medicines or as food items. Thus, this study was aimed to evaluate the potential consequence of oral co-administration of hydroalcoholic fruit extract of Balanites aegyptiaca and leaf latex of Aloe camperi on the antimalarial effectiveness of chloroqine. Extract alone and extract in combination with chloroquine were tested against plasmodium berghie infected mice using peters four day suppressive method. Acute toxicity study was also carried out. The present study revealed that concurrent administrations of leaf extract of Balanites aegyptiaca and leaf leatx of Aloe camperi was found to increase parasitemia suppression potential of chloroquine. From the study it can be concluded that Balanites aegyptiaca and leaf leatx of Aloe camperi can potentiate malaria suppression of chloroquine.

Keywords: Aloe camperi, Balanites aegyptiaca, Chloroquine, Concurrent use, Consequence, Malaria.

\section{INTRODUCTION}

The use of herbal medicines (HM) is on the rise among the global population. Although the safety profile of many herbal medicines is promising, accumulated data show evidence of significant interactions with medications, which can place individual patients at great risk. Worldwide, most HM can be obtained without a prescription from various sources. The evidence from the literature that HM has pharmacological effects and may lead to adverse interactions when co-administered with prescription medicines has grown ${ }^{[1]}$.

Most natural products, unlike conventional drugs, are a complex mixture of chemical constituents. Often a complete characterization of the bioactive compounds from an herbal is unknown. Additionally, the chemical makeup of natural products varies depending on the part of the plant used, climate, growing conditions, harvesting, and storage conditions. The complex nature and the manufacturing process of a natural product complicate the determination of herb-drug interactions ${ }^{[2]}$. Some medicinal and/or food plants, alter some pharmacokinetic parameters of chloroquine through interfering with its absorption, distribution or elimination consequently either increase or decrease blood level of chloroquine when concurrently consumed ${ }^{[3]}$. Muregi et al (2007) reported that chloroquine in combination with methanolic extracts of Albizia gummifera, Ficus sur, Rhamnus prinoides and Rhamnus staddo, Caesalpinia volkensii, Maytenus senegalensis, Withania somnifera, Ekebergia capensis, Toddalia asiatica and Vernonia lasiopus were found to have statistically significant and improved suppressions ${ }^{[4]}$, while Azadirachta indica tend to reduce serum levels of chloroquine decreasing suppression outcome of chloroquine ${ }^{[3]}$.

Plants commonly used in traditional medicine are assumed to be safe due to their long usage in the treatment of diseases according to knowledge accumulated over centuries ${ }^{[5]}$. Taking the above considerations in to account, this project was aimed to evaluate the potential consequences of concurrent use of chloroquine with hydroalcoholic extracts of traditional used local medicinal plants Balanites aegyptiaca and leaf leatx of Aloe camperi on the antimalarial efficacy of chloroquine.

\section{MATERIALS AND METHODS}

\section{Plant Collection and preparation}

Ethnobotanic information, about folklore use and concurrent use of herbal preparations with chloroquine 
with a voucher specimen and transported to the Laboratory of was retrieved from local informants (Traditional medicine practitioners, local peoples and herbal sellers) through semi-structured interview so as to select plants for the study. Fresh fruits of Balanites aegyptiaca and leaf latex of Aloe camperi were collected from the Ethiopian flora for the experimentation in February 2015. Sample specimen for Balanites aegyptiaca (collection number GG004) and Aloe camperi (collection number GG002) was collected and authenticated by botanist at addis Ababa University, Biology department; and sample specimen was deposited for further reference.

\section{Extract preparation}

Crude extracts of Balanites aegyptiaca was prepared from air dried powdered fruits using $70 \%$ ethanol following the procedures described by Mukherejee, ${ }^{[6]}$ and the leaf leatx of Aloe camperi was collected from by concentrating the leaves around a plate. Stock solution of test extracts (TEs) (1000 mg/kg body weight) and chloroquine (CQ) phosphate $(25 \mathrm{mg} / \mathrm{kg}$ body weight) was prepared using distilled water. Mixing equal volumes of TE and CQ stock solutions produced TE-CQ mixture (TE, $500 \mathrm{mg} / \mathrm{kg}, \mathrm{CQ}, 12.5 \mathrm{mg} / \mathrm{kg}$ body weight). Test samples was comprised of distilled water (-ve control), TEs $(500 \mathrm{mg} / \mathrm{kg} \mathrm{bw}), \mathrm{TE}+\mathrm{CQ}$ mixture $(500+12.5 \mathrm{mg} / \mathrm{kg}$ bw), and CQ $(12.5 \mathrm{mg} / \mathrm{kg} \mathrm{bw},+\mathrm{ve}$ control). Finally extracts of fruits of $B$. aegyptiaca and leaf leatx of $A$. camperi and extract in combination with chloroquine (CQ) were prepared for further activity.

\section{In vivo Antiplasmodial Activity Evaluation: 4-day suppressive test}

All experiments were carried out after approval from Institutional Review committee of the College of Health Sciences, Mekelle University. Plasmodium berghei infected donor mice was obtained from the Ethiopian public health institute, Addis Ababa. Acute oral toxicity study was performed as per Organization for Economic Cooperation and Development guidelines $425{ }^{[7]}$. The test protocol was based on the 4-day peters suppressive test. Swiss albino mice of both sexes (8-12 weeks of age) were used during the study. Parasitized erythrocytes were obtained from the jugular vein of $P$. bergie infected donor mouse. The study animals were grouped in to six group having five mice per group where group-I provided with fruit extract of Balanites aegyptiaca $(500 \mathrm{mg} / \mathrm{kg})$, group -II received $500 \mathrm{mg} / \mathrm{kg}$ leaf leatx of Aloe camperi (AC), group-III: chloroquine (CQ) and
Balanites aegyptiaca $(12.5 \mathrm{mg} / \mathrm{kg} \mathrm{CQ}+500 \mathrm{mg} / \mathrm{kg} \mathrm{BEF})$, group-VI: Chloroquine and leaf leatx of Aloe camperi $(12.5 \mathrm{mg} / \mathrm{kg}$ CQ $+500 \mathrm{mg} / \mathrm{kg} \mathrm{AC}$ ), group $\mathrm{V}: 12.5 \mathrm{mg} / \mathrm{kg}$ chloroquine (CQ) and groupVI: received $10 \mathrm{ml} / \mathrm{kg}$ distilled water respectively. All animals were infected with $0.2 \mathrm{ml}$ suspension- expected to contain $1 \times 10^{7}$ infected erythrocytes (IE) of $P$. berghei intraperitonially (IP) in day one. 2-3 hrs post infection test samples were administered orally using standard oral gavages. Treatment was continued until the fourth day. In day five blood samples were taken from the tail of each mouse and a thin blood films were prepared, fixed with methanol and stained using Giemsa stain (10\%) and observed microscopically with a magnification power of 100X. Levels of blood parasite and the average percent parasite suppression were calculated as follows:

$$
\begin{gathered}
\% \text { Parasitaemia }=\frac{\text { Number of parasitized RBC }}{\text { Total number of RBC count }} \times 100 \\
\% \text { Suppression }=\left[\frac{(\text { Mean parasitemia of negative control- Mean parasitaemia of treated })}{\text { Mean parasitemia of negative control }} \times 100\right.
\end{gathered}
$$

\section{Data analysis}

The data were expressed as Mean \pm Standard error of mean $(M \pm$ SEM). The differences between means were analyzed using windows SPSS Version 16 and comparison of parasitaemia among groups was determined using one-way ANOVA and post hoc analysis using Tukey's-HSD-test. The $\mathrm{P}$ values $<0.05$ were considered as significant.

\section{RESULTS AND DISCUSSION}

The results of acute toxicity study indicated that there were no visible signs of toxicity and mortality observed in any animals within $24 \mathrm{~h}$, and for the next 14 days after oral administration of the extracts, at a dose up to $2000 \mathrm{mg} / \mathrm{kg}$ body weight.

The percentage suppression of $P$. berghei in mice was found insignificant after oral administration of Balanites aegyptiaca fruit extract and leaf latex of $A$. camperi only as compared to those received extract in combination with chloroquine. However study animals which recieved Balanites aegyptiaca fruit extract were found to have significant parasitemia suppression as compared to control groups provided with distilled water (Table 1).

Table 1: Percentage suppression of $P$. berghei in mice after treatment of the hydroalcoholic extract of BEF, leaf latex of AC and in combination CQ

\begin{tabular}{lllll}
\hline Group & Drug/Extract & Dose $(\mathrm{mg} / \mathrm{kg} /$ day $)$ & $\%$ Parasitaemia \pm SEM & \% Suppression \\
& & & & $57.1^{*^{\mathrm{a}}}$ \\
Group-1 & BEF & 500 & $18 \pm 0.07$ & 35.2 \\
Group-2 & AC & 500 & $27.2 \pm 0.11$ & 99.5 \\
Group-3 & BEF+ CQ & $500+12.5$ & $0.2 \pm 0.002$ & 95.2 \\
Group-4 & AC+ CQ & $500+12.5$ & $2.8 \pm 0.01$ & 93.3 \\
Group-5 & CQ & 12.5 & $42 \pm 0.05$ & 0.00 \\
Group-6 & Dist.Water & $10 \mathrm{ml} / \mathrm{Kg}$ & 2.04 & \\
\hline
\end{tabular}

Values are presented as $\mathrm{M} \pm \mathrm{SEM} ; \mathrm{n}=5 ;{ }^{*} P<0.05$; suppression was significant; a = comparison with that of the negative control; BEF; Balanites aegyptiaca fruit, AC; Aloe camperi, CQ; Chloroquine

Table 2: Body weight and mean survival time of $P$. berghei infected mice after the administration of extract and, extract and chloroquine

\begin{tabular}{|c|c|c|c|c|c|c|}
\hline Group & Drug/Extract & $\begin{array}{l}\text { Dose } \\
\text { /day) }\end{array}$ & Wt $\mathrm{D}_{0} \pm \mathrm{SEM}$ & Wt D $\mathrm{D}_{4} \pm \mathrm{SEM}$ & $\begin{array}{l}\text { Wt Mean } \\
\text { difference } \\
\left(\mathrm{D}_{4-} \mathrm{D}_{0}\right)\end{array}$ & MST \\
\hline Group-1 & $\mathrm{BEF}$ & 500 & $24.6 \pm 1.3$ & $18.8 \pm 4.2$ & -5.6 & $11 \pm 1.0$ \\
\hline Group-2 & $\mathrm{AC}$ & 500 & $23.4 \pm 0.5$ & $31.4 \pm 2.2$ & 8 & $9.6 \pm 0.8$ \\
\hline Group-3 & $\mathrm{BEF}+\mathrm{CQ}$ & $500+12.5$ & $19.3 \pm 0.48$ & $25.2 \pm 0.7$ & 5.9 & $15.5 \pm 1.3$ \\
\hline Group-4 & $\mathrm{AC}+\mathrm{CQ}$ & $500+12.5$ & $31.8 \pm 0.48$ & $27.4 \pm 1.6$ & -4.4 & $12.3 \pm 0.3$ \\
\hline Group-5 & CQ & 12.5 & $17.3 \pm 0.33$ & $18.8 \pm 0.5$ & 1.5 & ND \\
\hline Group-6 & Dist.Water & $10 \mathrm{ml} / \mathrm{Kg}$ & $28.5 \pm 0.87$ & $24.8 \pm 0.9$ & -3.7 & $9.3 \pm 1.0$ \\
\hline
\end{tabular}
combination

follow-up (28-days). BEF; Balanites aegyptiaca fruit, AC; Aloe camperi, CQ; Chloroquine 
Body weight and mean survival time of Plasmodim berghei infected mice were higher in groups treated with extract and chloroquine combination than study animals provided with extract only though they were found to be lower than those treated with chloroquine phosphate (Table 2).

The results of the present study showed that the Balanites aegyptiaca fruit extract showed significant anti-plasmodial activity when it is given extract only and in combination with chloroquine too. On the contrary of leaf latex of aloe camperi revealed it had weak antimalarial activity but when co-administrated with chloroquine it seems it has weak effect on chloroquine (Figure1).

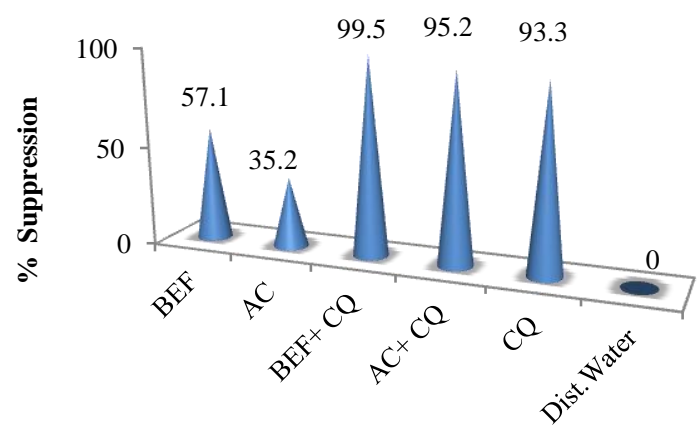

Figure 1: Percent suppression of Balanites aegyptiaca fruit and leaf latex of Aloe camperi in combination with chloroquine

Some medicinal and/or food plants, when concurrently consumed with drugs, are known to affect the way in which the body handles drugs and therefore have the potentials to either increase or decrease a drug's therapeutic or adverse effects. Some plant materials alter some pharmacokinetic parameters of chloroquine through interfering with its absorption, distribution or elimination. For example, while grapefruit juice and spinach increased blood level of chloroquine; Gnetum africana and Azadirachta indica ${ }^{[8]}$ tend to reduce serum levels of chloroquine ${ }^{[3]}$, ethanol extract of Vernonia amygdalina leaves ${ }^{[9]}$; ethanol extract of Telfairia occidentalis leaves ${ }^{[10]}$; and ethanolic extract of Heinsia crinata leaves ${ }^{[11]}$ were shown to impair the bioavailability and decreased some of the pharmacokinetic parameters of chloroquine and thereby my render it ineffective. Thus, positive and negative effect seen on the parasitemia suppression potential of the medicinal plants may due to the above mentioned mechanisms.

In addition, the other parameter used to evaluate the efficacy of antimalarial plant extract is mean survival time ${ }^{[12]}$. The mean survival time of mice treated with chloroquine in combination with extracts were shown to be high as compared to extract only treated groups, which was statistically significant $(P<0.05)$ but survived less as compared to chloroquine alone treated groups (Table 2 ).

\section{CONCLUSION}

The present study justifies the antimalarial activity potential of the medicinal plants. More over Balanites aegyptiaca fruit extract significantly increased malaria suppression outcomes of chloroquine and leaf latex of Aloe camperi potentiate were found to have less positive effect on the suppression potential of chloroquine.

\section{Acknowledgments}

To Mekelle University for sponsoring the grant to accomplish the project and to Addis Ababa University, school of pharmacy for providing laboratory facilities.

\section{REFERENCES}

1. Skalli A.U.S., Zaid A., Soulaymani R. Drug Interactions with Herbal Medicines. Ther Drug Monit. 2007; 29 (6): 1-8.

2. MacKinnon K. J., Swanson S.L. Herbal-Drug Interactions. InetCE. 2005; $9(10): 1-30$.

3. Eseyin O., Ebong A., Ubobre A., Ekarika J., Udo I. Changes in Some Pharmacokinetics parameters of chloroquine by Gnetum africana. Macedonian Journal of Medical Sciences. 2012; 1857-5773.

4. Muregi F.W., Ishih A., Miyase T., Suzuki T., Kino H., Amano T. et al. Antimalarial activity of methanolic extracts from plants used in Kenyan ethnomedicine and their interactions with chloroquine (CQ) against a CQ-tolerant rodent parasite, in mice. Journal of Ethnopharmacology. 2007; 111(1): 190-195

5. Jeruto P., Nyangacha R. M., Mutai C. In vitro and in vivo antiplasmodial activity of extracts of selected Kenyan medicinal plants. Afr. J. Pharm. Pharmacol. 2015; 9(16): 500-505.

6. Mukherejee P.K. Quality control of herbal drugs; an approach to evaluation of botanicals. Business Horizons pharmaceutical publishers, 2002 .

7. Organisation for Economic Co-operation (OECD 425). OECD guidelines for the testing of chemicals: Acute Oral Toxicity Up and DownProcedure (UDP), 2008, pp. 1-27.

8. Nwafor S.V., Akah P.A., Okoli C.O., Onyirioha A.C., Nworu C.S. Interaction between chloroquine sulphate and aqueous extract of Azadirachta indica A. Juss (Meliaceae) in rabbits. Acta Pharm. 200; 353(4):305-11.

9. Igboasoiyia C., Eseyin O.A., Udoma N.F. The effect of ethanolic extract of Vernonia amygdalina leaves on some pharmacokinetics parameters of chloroquine in rats. Research Journal of Pharmacology. 2008; 2 (2): 2427

10. Eseyin O.A., Edoho E.J., Igboasoiyi A.C., Nwadiukwu E.G., Ekpo A. Effects of the leaf extract of Telfairia occidentalis on the pharmacokinetics of chloroquine. International Journal of Biological Chemistry 2007; 01(4):256-260.

11. Eseyin, Olorunfemi, Ebong, Aniekan, Attih, Emmanuel, Imo Udoh. Effects of the leaf of Heinsia crinata on the pharmacokinetics of chloroquine in rats. International Journal of Biological \& Pharmaceutical Research. 2010; 1(2): 88-93.

12. David A.F., Philip J.R., Simon I.C., Reto B., Solomon N. Antimalarial drug discovery: Efficacy models for compound screening. Nature Reviews. 2004; 3: 509-520.

\section{HOW TO CITE THIS ARTICLE}

Sibhat GG, Hiben MG. Consequence of concurrent use of chloroquine and hydroalcoholic extract of Balanites aegyptiaca and leaf leatx of Aloe camperi. The Journal of Phytopharmacology 2016;5(1):35-37. 